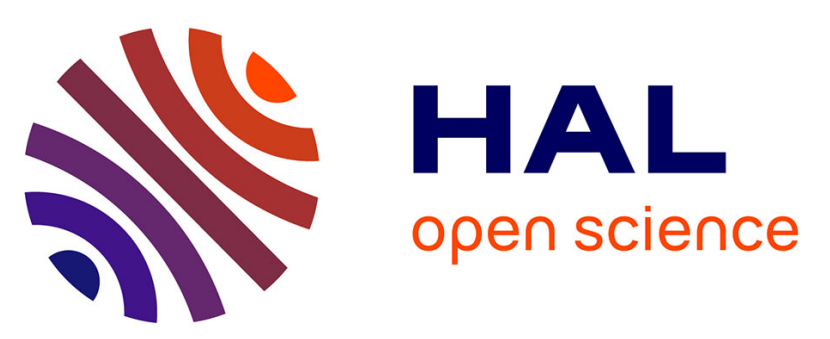

\title{
Toward a Standardization of Ultrasound Scanners for Dynamic Contrast-Enhanced Ultrasonography: Methodology and Phantoms
}

Stéphanie Pitre, Bénédicte Coiffier, Laurène Jourdain, Baya Benatsou, Ingrid Leguerney, Nathalie Lassau

\section{To cite this version:}

Stéphanie Pitre, Bénédicte Coiffier, Laurène Jourdain, Baya Benatsou, Ingrid Leguerney, et al.. Toward a Standardization of Ultrasound Scanners for Dynamic Contrast-Enhanced Ultrasonography: Methodology and Phantoms. Ultrasound in Medicine \& Biology, 2017, 43 (11), pp.2670 - 2677. 10.1016/j.ultrasmedbio.2017.06.032 . hal-03307576

\section{HAL Id: hal-03307576 https://hal.science/hal-03307576}

Submitted on 29 Jul 2021

HAL is a multi-disciplinary open access archive for the deposit and dissemination of scientific research documents, whether they are published or not. The documents may come from teaching and research institutions in France or abroad, or from public or private research centers.
L'archive ouverte pluridisciplinaire HAL, est destinée au dépôt et à la diffusion de documents scientifiques de niveau recherche, publiés ou non, émanant des établissements d'enseignement et de recherche français ou étrangers, des laboratoires publics ou privés. 


\title{
TOWARD A STANDARDIZATION OF ULTRASOUND SCANNERS FOR DYNAMICCONTRAST-ENHANCED ULTRASONOGRAPHY: METHODOLOGY AND PHANTOMS
}

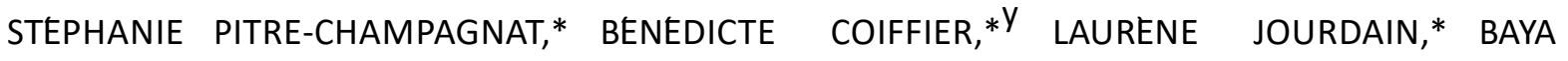 \\ BENATSOU, ${ }^{\mathrm{Y}}{ }^{\mathrm{INGRID}}$ LEGUERNEY ${ }^{*} \mathrm{Y}$ and NATHALIE LASSAU $* \mathrm{Y}$ \\ * University Paris-Sud CNRS, Université Paris-Saclay, Villejuif, France; and ${ }^{\mathrm{V}}$ Gustave Roussy, Villejuif, \\ France
}

(Received 25 August 2016; revised 28 June 2017; in final form 30 June 2017)

\begin{abstract}
The standardization of ultrasound scanners for dynamic contrast-enhanced ultrasonography (DCE- US) is mandatory for evaluation of clinical multicenter studies. We propose a robust method using a phantom for measuring the variation of the harmonic signal intensity obtained from the area under the time-intensity curve versus various contrast-agent concentrations. The slope of this measured curve is the calibration parameter. Wetested our method on two devices from the same manufacturer (AplioXV and Aplio500, Toshiba, Tokyo, Japan) using the same settings as defined for a French multicenter study. The Aplio500's settings were adjusted to match the slopes of the AplioXV, resulting in the following settings on the Aplio500: at 3.5 MHz: MI 5 0.15; CG $535 \mathrm{~dB}$ and at $8 \mathrm{MHz}$ : MI 5 0.10; CG $532 \mathrm{~dB}$. This calibration method is very important for future DCE-US multicenter studies. (E-mail: stephanie.pitre@u-psud.fr) (C) 2017 World Federation for Ultrasound in Medicine \& Biology.

Key Words: Dynamic contrast-enhanced ultrasound (DCE-US), Methodologies of ultrasound calibration, Flow phantom.
\end{abstract}

Address correspondence to: Stéphanie Pitre-Champagnat, IR4 M UMR 8081- University Paris Sud, 114 rue Edouard Vaillant, 94805 Villejuif, France. E-mail: stephanie.pitre@u-psud.fr 


\section{Introduction}

Dynamic contrast-enhanced ultrasound (DCE-US) is a functional imaging modality dedicated to the quantitative assessment of tissue micro-vascularization in cardiologyand oncology. In oncology, the quantitative approach is essential to evaluate therapeutic efficiency with monitoring of the progression of tumor vascularization. Despite several guidelines and many published clinical studies (Claudon et al. 2013; Dietrich et al. 2012; Lassau et al. 2010, 2011; Piscaglia et al. 2012), thisimaging technique is still rarely used for the assessment of tumor responses, which require the quantification of ultrasound images with rigorous methodology to analyze the time-intensity curves (TICs). A French multi-centric study (2007-2010), which included 539 patients with solid tumors who were treated with antiangiogenic drugs, was performed with a standardized procedure of both acquisition and DCE-US quantification (Lassau et al. 2012). A DCE-US perfusion parameter, the area under the curve (AUC) was validated as a biomarker at 1 month with a cut-off of $40 \%$ of AUC to predict efficiency of treatments (Lassau et al. 2014).

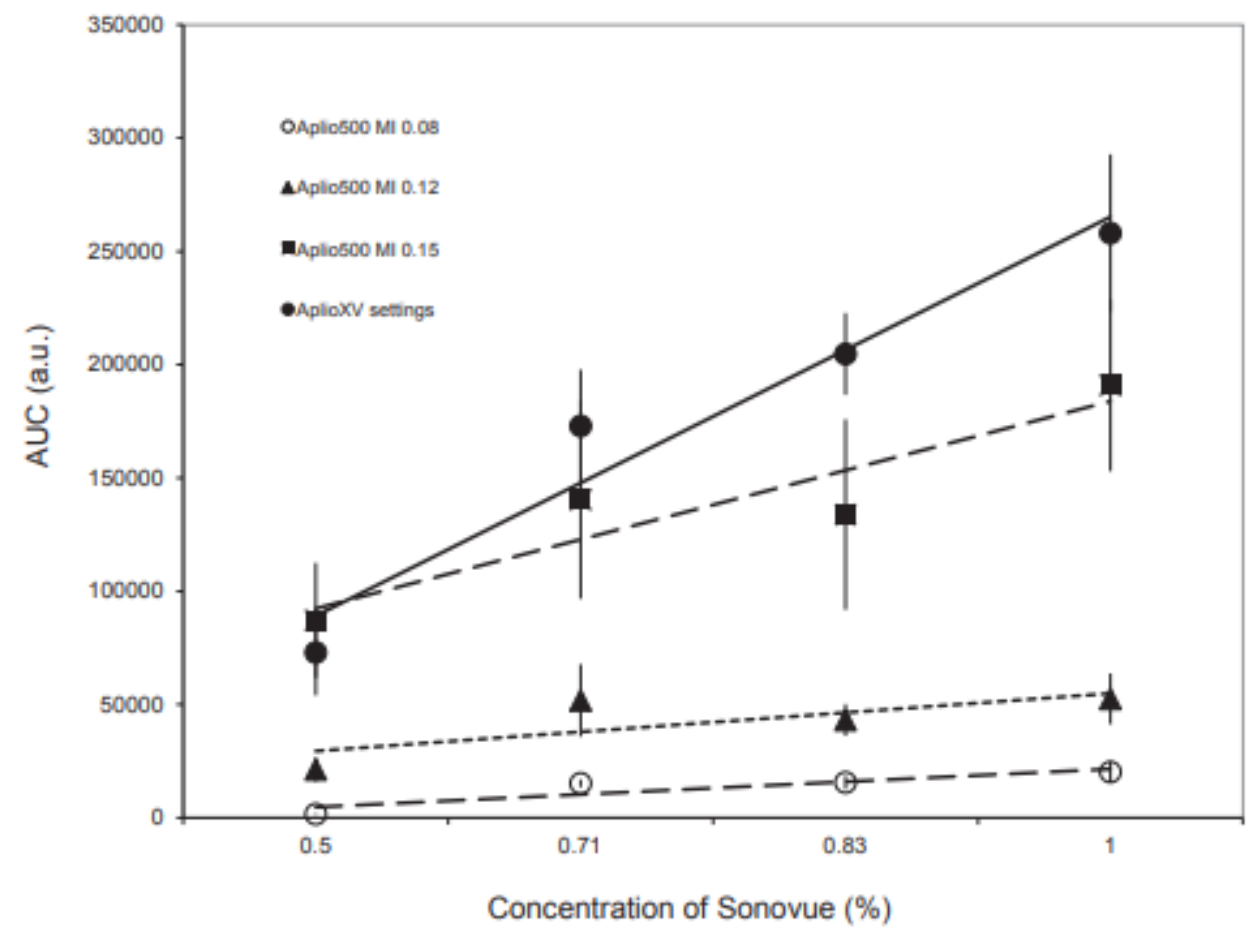

Fig. 2. Impact of varying concentration of contrast agents on AUC (arbitrary unit) at $3 \mathrm{MI}(0.08,0.12$ and 0.15 , respectively). The linear relationship obtained with the AplioXV (Toshiba Medical System, Tokyo, Japan) was also plotted. Measurements were performed with the abdominal curvilinear probe PVT-375 BT $(3.5 \mathrm{MHz})$. AUC = area under the curve; $\mathrm{MI}=$ mechanical index.

One of the levers to the dissemination of the DCE- US method is the standardization of ultrasound scannersfor a homogeneous quantification of tumor perfusion. Inpractice, each type of ultrasound scanner has its own settings and yet no common standard exists. The same settings on two different ultrasound systems do not mea-sure the same signal, making it difficult to transfer acquisition protocols of one type of ultrasound systemto another. So, when predictive values of tumor vasculature are identified by a clinical study, these can only be exploited by imaging departments that have the same model of ultrasound scanner, the same probes and the same settings, as was the case in the French multicentricstudy. This constraint contributes to the limitation of thedissemination of the DCE-US imaging method. The challenge now is to take into account the diversity of ultrasound and instrumental developments while maintaining the predictive values of therapeutic response established through clinical studies. Radiologists have indicated the need to standardize DCE-techniques toassess functional imaging biomarkers (Katabathina et al. 2012; O'Connor et al. 2017; Sullivan et al. 2015). The standardization of ultrasound scanners in contrast mode 
must be performed by in vitro studies with dedicated test objects or phantoms. These arecurrently used in quantitative imaging positronemission tomography/computed tomography (PET/CT) and PET/magnetic resonance (PET/MR) systems(Boellaard et al. 2015) to evaluate and control the performance of the devices. In the field of DCE-US, phan- toms are mainly used to evaluate methodologicaldevelopments. Indeed, many teams studied blood flow with a phantom based on a renal dialysis cartridge, described first by Hindle and Perkins (1994). This phan-tom with parallel tubes of $200 \mathrm{~mm}$ with cellulose walls, reproduced the physiologic conditions of the microvasculature with laminar flow. This phantom was used in particular to assess quantification methods (Claassen et al. 2001; Gauthier et al. 2011a, 2012b; Kier et al. 2009; Li et al. 2002; Lohmaier et al. 2004; Lucidarme et al. 2003; Quaia et al. 2009; Ugolini et al. 2000; Veltmann et al. 2002) and to characterize novel ultrasound contrast agents (Casciaro, et al. 2009; Lavisse et al. 2008; Radhakrishnan et al. 2012). This type of phantom is still difficult to use forreproducibility studies because of its delicate implementation. Another category of phantom consists of a single tube, a design well adapted forrepeatability studies (Gauthier et al. 2011a), and also used to assess new contrast agents (Lavisse et al. 2008; Radhakrishnan et al. 2012) or new quantification methods (Bruce et al. 2004; Gauthier et al. 2012a,b; Lampaskis and Averkiou 2010). Finally, a versatile liver machine perfusion system was developed for ex vivo DCE-US assessment. However, to date, we find neither in vitro phantom nor methodology that is dedicated to calibrate ultrasound scanners, thefirst step for standardization of DCEUS imaging.

The aim of our study is to validate a robust method toestablish the calibration in contrast mode of two differentultrasound scanners using settings initially defined for a French multicenter study. To this purpose, the calibration method was based on variations of the enhanced signal in-tensity with a range of concentrations of contrast agent.

\section{MATERIALS AND METHODS}

\section{Ultrasound scanners}

Two ultrasound scanners were studied. The first was the ultrasonograph used for the clinical validation of DCE-US in predicting outcomes of antiangiogenic therapy for solid tumors (Lassau et al. 2014): AplioXV (Toshiba Medical System, Tokyo, Japan). The other was the latest ultrasound scanner Aplio500 (Toshiba Medical System) In our study, the search for settings havingsimilar performance between the two echographs was performed with three probes: the abdominal curvilinear probe PVT-375 BT (3.5 MHz) for both ultrasound scan-ners, and the linear probe PVT-805 AT ( $8 \mathrm{MHz}$ ) for the AplioXV, compared with the new dedicated probe PLT-1005 BT (10 MHz) for the Aplio500. Two setting param-eters can adjust the DCE-US response: mechanical index(MI) and color gain (CG). To avoid destruction of the microbubbles, MI must be strictly ,0.2. We chose to avoid exceeding an MI of 0.15. The parameter CG modifies thegain of an analogue amplifier of the probe and acts both on the collected signal and on the noise. In separate experiments, we varied the $\mathrm{MI}$ and the CG to change the dynamics of Aplio500 to obtain the same dynamics as the AplioXV, the reference in the French multicentric proto-col. All settings are summarized in Table 1. Therefore, we determined the settings of the Aplio500 in two steps: determination of the optimum MI with an arbitrary valueof CG, and then determination of the optimum CG with the value of the fixed MI. The acoustic power (AP) was determined in the function of $\mathrm{MI}$, to as low a level as possible. 


\begin{tabular}{|c|c|c|c|c|}
\hline \multirow[b]{2}{*}{ Setting parameters } & \multicolumn{2}{|c|}{ Settings of AplioXV* } & \multicolumn{2}{|c|}{ Settings of Aplio500* } \\
\hline & $\begin{array}{l}\text { Curvilinear probe } \\
\text { PVT-375 BT }\end{array}$ & $\begin{array}{l}\text { Linear probe } \\
\text { PVT-805 AT }\end{array}$ & $\begin{array}{l}\text { Curvilinear probe } \\
\text { PVT-375 BT }\end{array}$ & $\begin{array}{l}\text { Linear probe } \\
\text { PLT-1005 BT }\end{array}$ \\
\hline Frequency $(\mathrm{MHz})$ & 4 & 12 & 4 & 12 \\
\hline$D R(d B)$ & 55 & 55 & 55 & 55 \\
\hline $\mathrm{Ml}$ & 0,1 & 0,1 & $\begin{array}{l}\text { To } \\
\text { determined be }\end{array}$ & $\begin{array}{l}\text { To be } \\
\text { determined be }\end{array}$ \\
\hline AP (\%) & 0,8 & 0,8 & Varying with MI & Varying with MI \\
\hline$C G(d B)$ & 32 & 37 & $\begin{array}{l}\text { To be } \\
\text { determined }\end{array}$ & $\begin{array}{l}\text { To be } \\
\text { determined be }\end{array}$ \\
\hline PRF & 3,9 & 8,8 & 3,9 & 8,8 \\
\hline VRh (MHz) & 3 & 5 & 3 & 5 \\
\hline filter & 2 & 2 & 2 & 2 \\
\hline Focal VRI (\%) & 50 & 50 & 50 & 50 \\
\hline Depth $(\mathrm{cm})$ & 12 & 4 & 12 & 4 \\
\hline
\end{tabular}

DR 5 dynamic range; MI 5 mechanical index; AP 5 acoustic power; CG 5 color gain; PRF 5 pulse repetition frequency; VRh 5 vascular receptionharmonic frequency (in Hertz); VRI 5 vascular recognition imaging.

* Toshiba Medical System, Tokyo, Japan.

\section{Method of the variation of concentrations}

This method was based on the ultrasonography (US) intensity linearly linked to the number of microbubbles (Correas et al. 2000; Lampaskis and Averkiou 2010). A mathematical description of the formation of ultrasound echoes in DCE-US imaging was proposed by Tang et al. (2008). In the case of the pulse inversion mode, the contrast agent echoes $E_{C A}$ can be defined as follows:

$$
E_{C A}=2 C(x) k H_{1}^{2} A_{1}^{2}(x) A_{2}(x) A_{n}^{2}(x) G(x)-G(x) N
$$

Here, $C(x)$ is the concentration of the contrast agents, $H_{1}$ is the amplitude of the initial pulse at the frequency $f_{0}, k$ is an arbitrary constant in relation with the non-linear scattering at the harmonic signal with frequency of $2 f_{0}$. The contrast agent echo is varied withthe attenuation $A$ in the medium: linear attenuation due to the tissue $A_{1}(x)$ and $A_{2}(x)$ at fundamental and second harmonic frequency, respectively, whereas $A_{n}(x)$ corre- sponds to the non-linear attenuation from the contrast agents. Finally, $G(x)$ depends on the imaging settings, including the system gain, beam and receive profilesand the electronic noise $\mathrm{N}$.

When no microbubbles exist between the probe andthe target, $A_{n}(x)$ will be assumed as unity. Moreover, thenoise $\mathrm{N}$ is considered to have a Gaussian distribution witha mean of 0 and a variance of $\mathrm{V}$. In the case of a target thatis fixed within a phantom, the mathematical description of the echo will be treated as independent of depth, and eqn 1 becomes:

$$
E_{C A}=S H^{2}{ }_{1} C
$$


where $S$ is a parameter proportional to the linear attenuation at a fixed depth and the imaging settings of the ultra-sound system. The calibration method considered eqn 2 and was based on the variation of the concentration of contrast agents $C$.

The contrast agent used was $0.1 \mathrm{~mL}$ of SonoVue (Bracco, Milan, Italy) injected into a circuit of water of $90 \mathrm{~mL}$. This volume was associated with the ratio routinely used for clinical examinations ( $4.8 \mathrm{~mL}$ of SonoVue for $5 \mathrm{~L}$ of blood). After conditioning SonoVue(Bracco) with $5-\mathrm{mL}$ sodium chloride, the obtained solution corresponds with the concentration, namely $C_{0}$ in the experiments. For the calibration methodology, the concentration values were determined depending on the feasibility of dilution, because the SonoVue (Bracco) is kept under pressure, which implied a dilution in its orig-inal vial. Four concentrations of SonoVue (Bracco) wereconsidered: $\mathrm{C}_{0} ; 0.83 \times \mathrm{C}_{0} ; 0.71 \times \mathrm{C}_{0}$; and $0.5 \times \mathrm{C}_{0}$. The various concentrations of SonoVue (Bracco) necessary for the experiment were therefore prepared from the $C_{0}$ concentration SonoVue (Bracco) vial to which physio- logic saline was added. Thus, for the $0.83 C_{0}, 0.71 C_{0}$ and $0.5 C_{0}$ concentrations, saline volumes of $1 \mathrm{~mL}, 2 \mathrm{~mL}$ and $5 \mathrm{~mL}$ were added, respectively. The concentration was only varied by a maximum factor of 2 to ensure agood linear relationship with backscattered intensity (Lampaskis and Averkiou 2010).

To study settings with the 2 different ultrasound probes, we developed 2 corresponding phantoms with a material mimicking the acoustic properties of tissue (Fig. 1). For the settings with the abdominal probe, a spherical phantom of $50-\mathrm{mm}$ diameter with agar-agargel was developed to obtain maximum peak intensities (PIs) from the TICs similar to those measured on 539 patients included in the French multicentric study (mean PI 5611 a.u. and range: 0-18920 a.u.). The gel used is $82.6 \%$ distilled water, $6 \%$ glycerol, 3\% of graphite and $0.4 \%$ preservative (Culjat et al. 2010; Madsen et al.1998). Acoustic properties are a velocity of $154865 \mathrm{~m} \cdot \mathrm{s}^{21}$ and an acoustic attenuation of $0.560 .01 \mathrm{~dB} \mathrm{~cm}{ }^{21} \mathrm{MHz}^{21}$.

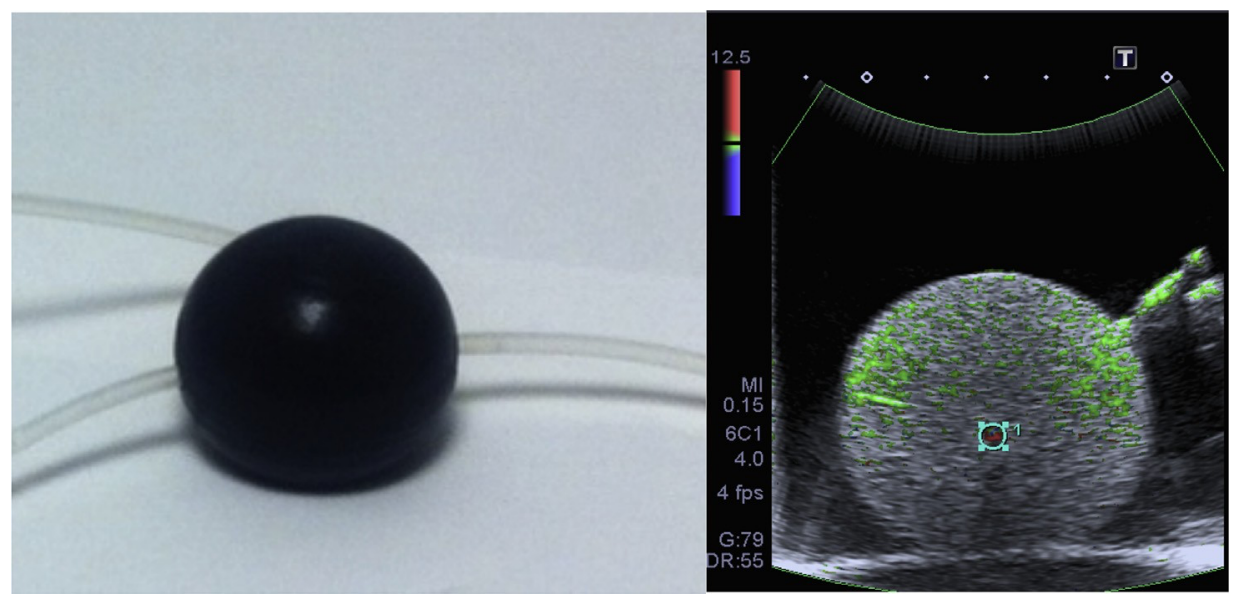

Fig. 1. Spherical phantom of 50-mm diameter with agar-agar gel and its contrast-enhanced ultrasound image obtained with a VRI-coded technique. VRI 5 vascular recognition imaging. 
A straight silicone tube of 2-mm inner diameter traversed this phantom. It was placed in a Polymethyl Methacrylate tank filled with water to facilitate the propagation of ultrasound to the probe, itself immersed in the tank opposite the phantom.The external dimensions of the tank were $27531053100 \mathrm{~mm}^{3}$ with foam absorbent on the internal walls to limit ultrasound reflections to the tank inter-faces. In the case of the linear probe, the ultrasonic attenuation at $7 \mathrm{MHz}$ is too high in tissues and limits the use of agaragar gel. Thus, the phantom was simplified to a silicone tube through the tank.

We designed a simple open-circuit flow model. Thefluid was non-degassed water at $20^{\circ} \mathrm{C}$ and was driven by a peristaltic pump (PumpDrive PD5101, Heidolph Instruments, Schwabach, Germany), providing a continuous non-pulsatile flow at $42.5 \mathrm{~mL} / \mathrm{min}$. A tube with an inner diameter of $2 \mathrm{~mm}$ and with a length of $1 \mathrm{~m}$ connectedthe pump to the phantom. This length is required to simulate the transit time of the TIC similar to that measured inthe study of 539 patients (mean transit time $520 \mathrm{~s}$ and range: $0-180 \mathrm{~s}$ ). The first step was to determine the reference dynamics of the AplioXV (Toshiba). Because these experiments have $12 \%$ of variability from the injection (Gauthier et al. 2012a), 8 acquisitions were performed for each of the 4 concentrations of SonoVue (Bracco) and for each parameter setting (MI and CG). For each acquisition, a 2min perfusion curve was recorded following the SonoVue (Bracco) injection. This step was carried out for curvilinear and linear probes.

\section{Data analysis}

The quantitative analysis was performed on the rawlinear data with the quantification software CHI-Q (Toshiba, Puteaux, France). Each acquisition involved a manual selection of the region of interest (ROI) selectedin the core tube. TICS, corresponding to the mean US intensity's temporal evolution induced by the contrast up- take and expressed in arbitrary units, were extractedautomatically from the quantification software (CHIQ quantification software, Toshiba Medical System, Tokyo, Japan). The TICs were then modeled using a mathematical model (date of issue: May 2008; name of company: Institut Gustave Roussy (Igr); Names of Inventors: N. Elie, N. Lassau, P. Peronneau, V. Rouffiac; French patent number: WO 2008053268 A1) to obtain the semi- quantitative perfusion parameter, area under the curve (AUC), which is recognized as the least variable (Gauthier et al. 2011a) and the most reliable for monitoring therapeutic efficacy on the patient (Lassau et al. 2014; O'Connor et al. 2017). In our study, the calibration of ultrasound scanners was obtained from the slope $S$ of the plot of concentration of SonoVue (Bracco) versus the AUC line. The aim was to obtainthe same $S$ value as that measured from the AplioXV (Toshiba Medical System) scanner. 


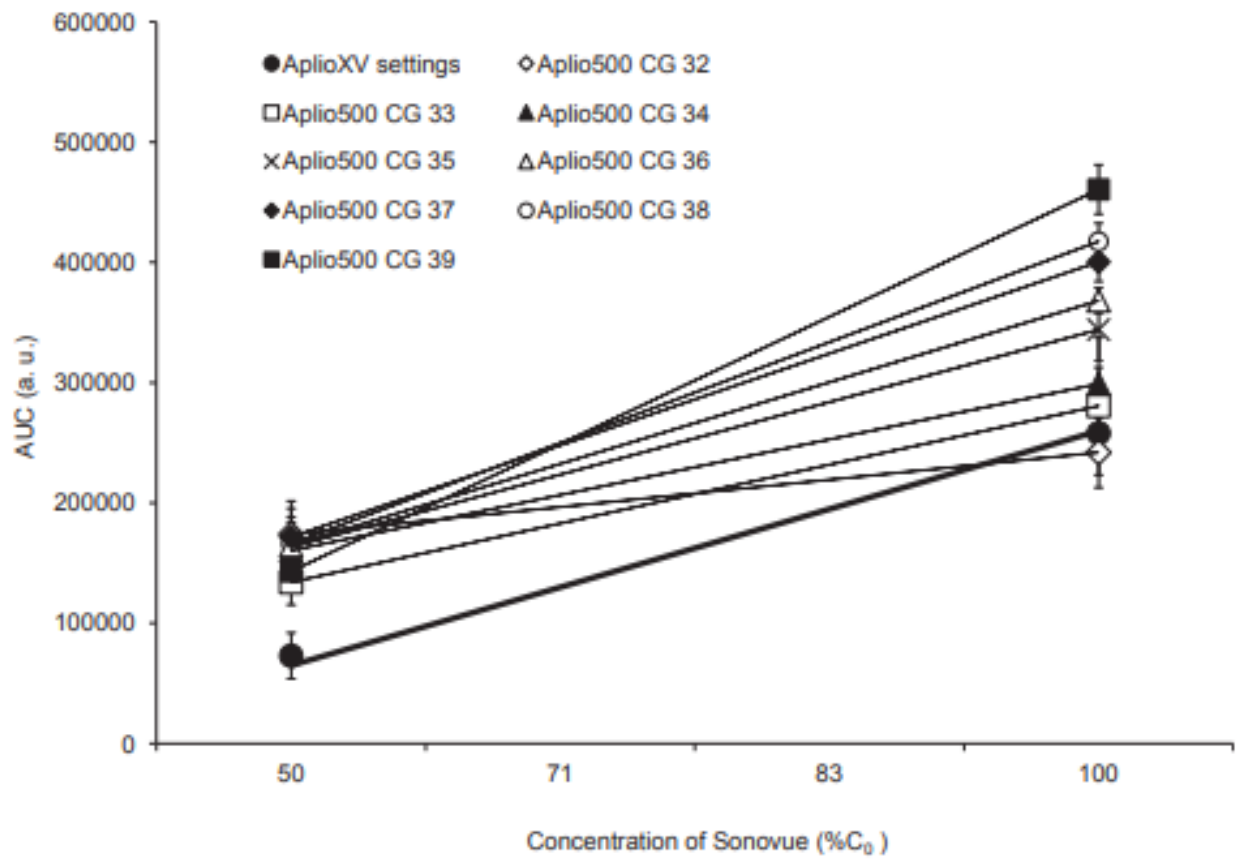

Fig. 3. AUC (a.u.) versus concentration of contrast agents curve at 8 CG (32-39 dB). The linear relationship obtained with the AplioXV (Toshiba Medical System, Tokyo, Japan) was also plotted. Measures were performed with the abdominal curvilinear probe PVT-375 BT (3.5 MHz). AUC = area under the curve; $\mathrm{CG}=$ color gain.

A calibration method for DCE-US - S. Ptrre-Champagnat et al.

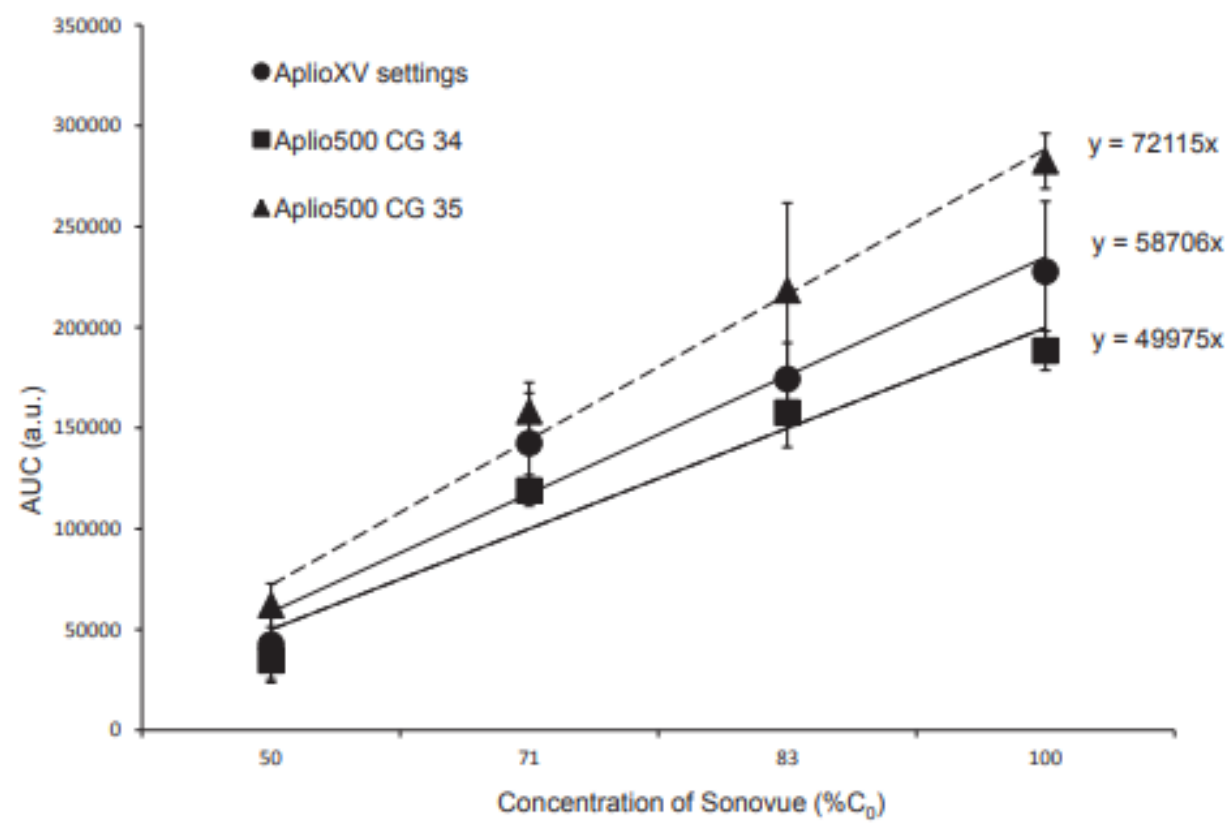

Fig. 4. AUC (a.u.) versus concentration of contrast agents versus curve at 2 CG ( 34 and $35 \mathrm{~dB}$, respectively). The linear function relationship obtained with the AplioXV (Toshiba Medical System, Tokyo, Japan) was also plotted. Measurements were performed with the abdominal curvilinear probe PVT-375 BT (3.5 MHz). AUC = area under the curve;

$$
\mathrm{CG}=\text { color gain }
$$




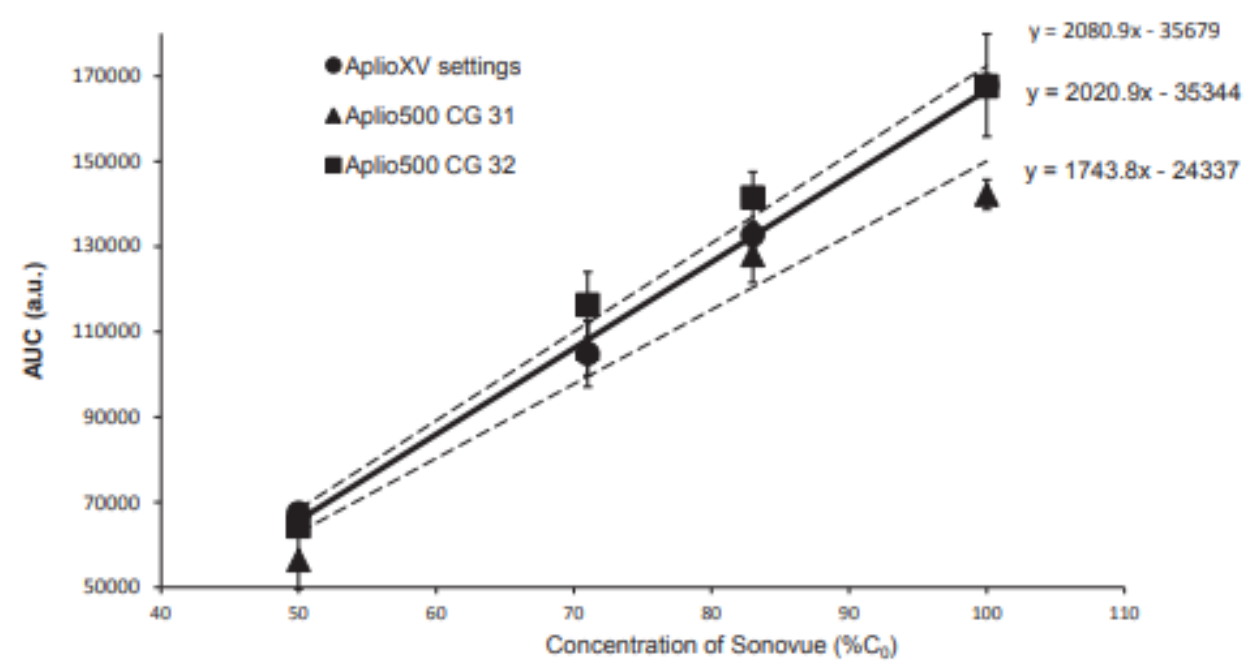

Fig. 5. AUC (a.u.) versus concentration of contrast agents curve at $2 \mathrm{CG}$ ( 31 and $32 \mathrm{~dB}$, respectively). With CG $=32$, the point at $50 \% \mathrm{C}_{0}$ coincides with the 1 obtained with the AplioXV (Toshiba Medical System, Tokyo, Japan), also plotted. Measurements were performed with the linear probe PVT-805 AT ( $8 \mathrm{MHz}$ ) for the AplioXV (Toshiba Medical System), and the probe PLT-1005 BT (10 MHz) for the Aplio500 (Toshiba Medical System). AUC = area under the curve; $\mathrm{CG}=$ color gain.

\section{RESULTS}

The results obtained with the abdominal probe for the 2 Aplio devices (Toshiba Medical System) are shownin Figure 2 with 3 mechanical indexes: 0.08, 0.12 and 0.15. AUC varies linearly with the concentration of Sono-Vue (Bracco), as expected, if one assumes proportionality between the number of microbubbles and the intensity ofthe detected ultrasonic signal. Furthermore, the increase of the MI is accompanied by an accentuation of the slopesof the linear regressions. Indeed, a high MI promotes theincrease of the amplitude of the ultrasonic signal. In accordance with Figure 2, the measurements with theMI 50.15 with the Aplio500 (Toshiba Medical System)appeared closest to those obtained with the AplioXV (Toshiba Medical System). Once fixed, MI studies have focused on the variation of the CG parameter and the re-sults are presented in Figure 3. In the first approach, a wide range of CG values were tested for each of the 2 extreme concentrations of SonoVue ([Bracco] at $\mathrm{CO}$ and $0.5 \times \mathrm{CO})$. The closest match of the slope $\mathrm{S}$ as obtained with the Aplio500 (Toshiba Medical System) was achieved with a CG of $34 \mathrm{~dB}$ on the AplioXV (Toshiba Medical System).

Subsequently, the study was conducted on a small number of CG close to the value $34 \mathrm{~dB}$ and with the 4 concentrations of SonoVue (Fig. 4). S (from eqn 2) were 49975 a.u. and 72115 a.u. for CG 534 dB and CG $535 \mathrm{~dB}$, respectively. When the $S$ was determined from the AplioXV (Toshiba Medical System), the value was at 58706 a.u. The greatest value of CG was chosen, because it optimizes the dynamics and thus limits a loss of information for the quantification of contrast agents. Thus, the settings of the Aplio500 (Toshiba Medical Sys-tem) that gave the same signal variations as the AplioXV(Toshiba Medical System), the reference scanner used forthe clinical protocol, were: MI 5 0.15; AP 5 0.75\%;

CG $535 \mathrm{~dB}$.

This approach was also conducted with the linear probe. The results obtained and summarized in Figure 5 indicate a setting of MI 5 0.10; AP $51 \%$; CG 532 dB. 


\section{DISCUSSION}

DCE-US applications are increasing in oncology (Hudson et al. 2015). The acceptance of this technique has increased around the world with the recent approval of SonoVue (Bracco) in the United States for abdominal applications. In all functional imaging techniques, the key word is the standardization of the methodology (O'Connor et al. 2017; Sullivan et al. 2015) in order to perform multicentric studies for the validation of biomarkers. Currently, the results of imaging biomarkers are very heterogeneous in monocentric studies in $\mathrm{MRI}$, and no validation has been performedin multicentric studies because no methodology has been developed to standardize the various machines from various companies. Quantitative approaches usedto assist guided therapeutic procedures remain limited because of the difficulty of standardizing the scannersin the contrast-enhanced mode. The Quantitative ImagingBiomarkers Alliance (QIBA, Oak Brook, IL, USA) fo- cuses task forces on standardization in order to propose clinical validations from multicentric studies conducted with various medical devices for each imaging modality.

In the field of quantitative tumoral perfusion, few multi-centric trials have been completed and none with multiple manufacturers. Moreover, device upgrades by manufacturers lead to difficulties in monitoring patients. In this context, our study provides a method for the calibration of an ultrasound scanner set-up based on the variations of contrast agent concentration. The first step, reported here, was to calibrate two devices from the same manufacturer.

Thus, without knowing the internal processing set- tings, the calibration method successfully determinedthe equivalent setting of another ultrasound system, the Aplio500 (Toshiba Medical System), to provide the same dynamic range of ultrasound intensity of AplioXV(Toshiba Medical System). The settings obtained with the curvilinear probe were MI 50.15 and CG $535 \mathrm{~dB}$, and

with the linear probes: MI 50.10 and CG $532 \mathrm{~dB}$.

Furthermore, the concentration method had a variability of $12 \%$. This calibration method has proven to be easily feasible with simple phantoms, manual injections of contrast agents and without de-gassed water. It should enable rapid reproduction of the French multicentric pro-tocol across the medical community.

Finally, this calibration phantom appears to be a promising tool toward the standardization of ultrasound scanners. However, this new method also needs to be tested with other scanners from various manufacturers and using various contrast agents. Additionally, in our study, we chose to determine the settings according to two acquisition parameters ( $\mathrm{MI}$ and $\mathrm{CG}$ ). However, we could have expanded to several more parameters. Inparticular, we did not vary the dynamic range, which also impacts on perfusion quantification only from com-pressed data (Gauthier et al. 2011b).

This method could be also used with other DCE-US quantification methods with a validated microvasculari- zation parameter.

\section{CONCLUSION}

In this study, we proposed a robust method to mea- sure the dynamic of signal for calibration of the Aplio ul-trasound scanners (Toshiba Medical System). The next new challenge is therefore to take into account the diver-sity of ultrasound scanners, with their various technolo- gies, to extend the use of DCE-US while maintaining predictive values of therapeutic response established from clinical studies.

Acknowledgments - The authors thank Stephen Randall Thomas of the IR4 M laboratory (University of ParisSud, Orsay, France) for valuablecomments and suggestions. This study was supported by a grant from the 
research program in physics, mathematics and engineering sciencesapplied to cancer research, of the French Plan Cancer 2013.

\section{REFERENCES}

Boellaard R, Rausch I, Beyer T, Delso G, Yaqub M, Quick HH, Sattler B. Quality control for quantitative multicenter wholebody PET/MR studies: A NEMA image quality phantom study with three current PET/MR systems. Med Phys 2015;42:5961-5969.

Bruce M, Averkiou M, Tiemann K, Lohmaier S, Powers J, Beach K. Vascular flow and perfusion imaging with ultrasound contrast agents. Ultrasound Med Biol 2004;30:735-743.

Casciaro S, Conversano F, Musio S, Casciaro E, Demitri C, Sannino A. Full experimental modelling of a liver tissue mimicking phantom for medical ultrasound studies employing different hydrogels. J Mater Sci Mater Med 2009;20:983-989.

Claassen L, Seidel G, Algermissen C. Quantification of flow rates usingharmonic grey-scale imaging and an ultrasound contrast agent: An in vitro and in vivo study. Ultrasound Med Biol 2001;27:83-88.

Claudon M, Dietrich CF, Choi Bl, Cosgrove DO, Kudo M, Nolsoe CP, Piscaglia F, Wilson SR, Barr RG, Chammas MC, Chaubal NG, Chen MH, Clevert DA, Correas JM, Ding H, Forsberg F, Fowlkes JB, Gibson RN, Goldberg BB, Lassau N, Leen EL, Mattrey RF, Moriyasu F, Solbiati L, Weskott HP, Xu HX, World Federation for Ultrasound in Medicine, European Federation of So-cieties for Ultrasound. Guidelines and good clinical practice recom-mendations for Contrast Enhanced Ultrasound (CEUS) in the liver-Update 2012: A WFUMB-EFSUMB initiative in cooperation with representatives of AFSUMB, AIUM, ASUM, FLAUS and ICUS. Ultrasound Med Biol 2013;39:187-210.

Correas JM, Burns PN, Lai X, Qi X. Infusion versus bolus of an ultra- sound contrast agent: in vivo dose-response measurements of BR1. Invest Radiol 2000;35:72-79.

Culjat MO, Goldenberg D, Tewari P, Singh RS. A review of tissue sub-stitutes for ultrasound imaging. Ultrasound Med Biol 2010;36:861-873.

Dietrich CF, Averkiou MA, Correas JM, Lassau N, Leen E, Piscaglia F.An EFSUMB introduction into Dynamic ContrastEnhanced Ultra-sound (DCE-US) for quantification of tumour perfusion. UltraschallMed 2012;33:344-351.

Gauthier M, Leguerney I, Thalmensi J, Chebil M, Parisot S, Peronneau P, Roche A, Lassau N. Estimation of intra-operator vari-ability in perfusion parameter measurements using DCE-US. WorldJ Radiol 2011a;3:70-81.

Gauthier M, Pitre-Champagnat S, Tabarout F, Leguerney I, Polrot M, Lassau N. Impact of the arterial input function on microvasculariza-tion parameter measurements using dynamic contrast-enhanced ul-trasonography. World J Radiol 2012a;4:291-301.

Gauthier M, Tabarout F, Leguerney I, Polrot M, Pitre S, Peronneau P, Lassau N. Assessment of quantitative perfusion parameters by dy- namic contrast-enhanced sonography using a deconvolution method: An in vitro and in vivo study. J Ultrasound Med 2012b; 31:595-608.

Gauthier TP, Averkiou MA, Leen EL. Perfusion quantification using dy- namic contrast-enhanced ultrasound: The impact of dynamic rangeand gain on time-intensity curves. Ultrasonics 2011b;51:102-106.

Gauthier TP, Chebil M, Peronneau P, Lassau N. In vitro evaluation of the impact of ultrasound scanner settings and contrast bolus volume ontime-intensity curves. Ultrasonics 2012c;52:12-19.

Hindle AJ, Perkins AC. A perfusion phantom for the evaluation of ultra-sound contrast agents. Ultrasound Med Biol 1994;20:309-314.

Hudson JM, Williams R, Tremblay-Darveau C, Sheeran PS, Milot L, Bjarnason GA, Burns PN. Dynamic contrast enhanced ultrasound for therapy monitoring. Eur J Radiol 2015;84:1650-1657.

Katabathina VS, Lassau N, Pedrosa I, Ng CS, Prasad SR. Evaluation oftreatment response in patients with metastatic renal cell carcinoma:Role of state-of-the-art cross-sectional imaging. Curr Urol Rep 2012;13:70-81.

Kier C, Meyer-Wiethe K, Seidel G, Mertins A. Improved modelling ofultrasound contrast agent diminution for blood perfusion analysis. Med Image Comput Comput Assist Interv 2009;12:935-942.

Lampaskis M, Averkiou M. Investigation of the relationship of nonlinear backscattered ultrasound intensity with microbubble concentration at low MI. Ultrasound Med Biol 2010;36:306-312. 
Lassau N, Bonastre J, Kind M, Vilgrain V, Lacroix J, Cuinet M, Taieb S, Aziza R, Sarran A, Labbe-Devilliers C, Gallix B, Lucidarme O, Ptak Y, Rocher L, Caquot LM, Chagnon S, Marion D, Luciani A, Feutray S, Uzan-Augui J, Coiffier B, Benastou B, Koscielny S. Vali-dation of dynamic contrast-enhanced ultrasound in predicting out- comes of antiangiogenic therapy for solid tumors: The Frenchmulticenter support for innovative and expensive techniques study. Invest Radiol 2014;49:794-800.

Lassau N, Chapotot L, Benatsou B, Vilgrain V, Kind M, Lacroix J, Cuinet M, Taieb S, Aziza R, Sarran A, Labbe C, Gallix B, Lucidarme O, Ptak Y, Rocher L, Caquot LM, Chagnon S, Marion D, Luciani A, Uzan-Augui J, Koscielny S. Standardization of dynamic contrast-enhanced ultrasound for the evaluation of anti-angiogenic therapies: The French multicenter Support for Innovativeand Expensive Techniques Study. Invest Radiol 2012;47:711716.

Lassau N, Koscielny S, Albiges L, Chami L, Benatsou B, Chebil M, Roche A, Escudier BJ. Metastatic renal cell carcinoma treatedwith sunitinib: Early evaluation of treatment response using dy- namic contrast-enhanced ultrasonography. Clin Cancer Res 2010; 16:1216-1225.

Lassau N, Koscielny S, Chami L, Chebil M, Benatsou B, Roche A, Ducreux M, Malka D, Boige V. Advanced hepatocellular carcinoma:Early evaluation of response to bevacizumab therapy at dynamic contrast-enhanced US with quantification-Preliminary results. Radiology $2011 ; 258: 291-300$.

Lavisse S, Peronneau P, Rouffiac V, Paci A, Vigouroux J, Opolon P, Roche A, Lassau N. Acoustic characterization of a new trisacryl contrast agent. Part II: Flow phantom study and in vivo quantifica-tion. Ultrasonics 2008;48:26-34.

Li PC, Yeh CK, Wang SW. Time-intensity-based volumetric flow mea-surements: An in vitro study. Ultrasound Med Biol $2002 ; 28: 349-358$.

Lohmaier S, Ghanem A, Veltmann C, Sommer T, Bruce M, Tiemann K. In vitro and in vivo studies on continuous echo-contrast applicationstrategies using SonoVue in a newly developed rotating pump setup.Ultrasound Med Biol 2004;30:1145-1151.

Lucidarme O, Kono Y, Corbeil J, Choi SH, Mattrey RF. Validation of ul-trasound contrast destruction imaging for flow quantification. Ultra-sound Med Biol 2003;29:1697-1704.

Madsen EL, Frank GR, Dong F. Liquid or solid ultrasonically tissue- mimicking materials with very low scatter. Ultrasound Med Biol 1998;24:535-542.

O'Connor JP, Aboagye EO, Adams JE, Aerts HJ, Barrington SF,Beer AJ, Boellaard R, Bohndiek SE, Brady M, Brown G, Buckley DL, Chenevert TL, Clarke LP, Collette S, Cook GJ, deSouza NM, Dickson JC, Dive C, Evelhoch JL, Faivre-Finn C, 
Gallagher FA, Gilbert FJ, Gillies RJ, Goh V, Griffiths JR, Groves AM, Halligan S, Harris AL, Hawkes DJ, Hoekstra OS, Huang EP, Hutton BF, Jackson $E F$, Jayson GC, Jones A, Koh DM, Lacombe D, Lambin P, Lassau N, Leach MO, Lee TY, Leen EL, Lewis JS, Liu Y, Lythgoe MF, Manoharan $P$, Maxwell RJ, Miles KA, Morgan B, Morris S, Ng T, Padhani AR, Parker GJ, Partridge M, Pathak AP, Peet AC, Punwani S, Reynolds AR, Robinson SP, Shankar LK, Sharma RA, Soloviev D, Stroobants S, Sullivan DC, Taylor SA, Tofts PS, Tozer GM, van Herk M, Walker-Samuel S, Wason J, Williams KJ, Workman P, Yankeelov TE, Brindle KM, McShane LM, Jackson A, Waterton JC. Imaging biomarker roadmap for cancer studies. Nat Rev Clin Oncol 2017;14:169-186.

Piscaglia F, Nolsoe C, Dietrich CF, Cosgrove DO, Gilja OH, Bachmann Nielsen M, Albrecht T, Barozzi L, Bertolotto M, Catalano O,Claudon M, Clevert DA, Correas JM, D’Onofrio M, Drudi FM, Eyding J, Giovannini M, Hocke M, Ignee A, Jung EM, Klauser AS, Lassau N, Leen E, Mathis G, Saftoiu A, Seidel G, Sidhu PS, ter Haar G, Timmerman D, Weskott HP. The EFSUMB Guidelines and Recommendations on the Clinical Practice of Contrast Enhanced Ultrasound (CEUS): Update 2011 on non- hepatic applications. Ultraschall Med 2012;33:33-59.

Quaia E, Nocentini A, Torelli L. Assessment of a new mathematical model for the computation of numerical parameters related to renalcortical blood flow and fractional blood volume by contrast- enhanced ultrasound. Ultrasound Med Biol 2009;35:616-627.

Radhakrishnan K, Haworth KJ, Huang SL, Klegerman ME, McPherson DD, Holland CK. Stability of echogenic liposomes asa blood pool ultrasound contrast agent in a physiologic flow phan- tom. Ultrasound Med Biol 2012;38:1970-1981.

Sullivan DC, Obuchowski NA, Kessler LG, Raunig DL, Gatsonis C, Huang EP, Kondratovich M, McShane LM, Reeves AP, Barboriak DP, Guimaraes AR, Wahl RL, Group R-QMW. Metrologystandards for quantitative imaging biomarkers. Radiology 2015;277:813-825.

Tang MX, Mari JM, Wells PN, Eckersley RJ. Attenuation correction inultrasound contrast agent imaging: Elementary theory and prelimi-nary experimental evaluation. Ultrasound Med Biol 2008;34: 1998-2008.

Ugolini P, Delouche A, Herment A, Diebold B. In vitro flow quantifica- tion with contrast power Doppler imaging. Ultrasound Med Biol 2000;26:113-120.

Veltmann C, Lohmaier S, Schlosser T, Shai S, Ehlgen A, Pohl C, Becher H, Tiemann K. On the design of a capillary flow phantom for the evaluation of ultrasound contrast agents at very low flow ve-locities. Ultrasound Med Biol 2002;28:625-634. 